\title{
Overall development of a bioprocess for the outdoor production of Nannochloropsis gaditana for aquaculture
}

\author{
Karina Riveros $^{1}$ | Claudia Sepulveda ${ }^{1}$ (D) | Jazmín Bazaes ${ }^{1}$ | Paola Marticorena ${ }^{1}$ | \\ Carlos Riquelme $^{1}$ | Gabriel Acién ${ }^{2}$
}

${ }^{1}$ Bio-innovation Centre, Antofagasta Institute, University of Antofagasta, Antofagasta, Chile

${ }^{2}$ Department of Chemical Engineering, University of Almería, Almería, Spain

Correspondence

Claudia Sepulveda, Bio-innovation Centre, Antofagasta Institute, University of Antofagasta, Chile.

Email: Claudia.sepulveda@uantof.cl

Funding information

Chilean Promotions Corporation (CORFO)

\begin{abstract}
In this paper, a systematic methodology is shown for the scaling-up of Nannochloropsis gaditana production for aquaculture uses. First, an adequate culture medium was developed, prepared using fertilizers instead of pure chemicals. Subsequently, the performance of $N$. gaditana was modelled as a function of average irradiance; this model being validated in continuous culture experiments. The model was used to determine the optimal dilution rate as well as the expected biomass concentration and productivity at optimal conditions. Finally, outdoor experiments were performed to confirm the model's validity and to determine optimal conditions at real production step. Biomass productivity values of up to $0.08 \mathrm{~g} \mathrm{~L}^{-1} \mathrm{day}^{-1}$ were obtained at an optimal dilution rate of 0.25 per day in $0.2 \mathrm{~m}$ wide flat-panel reactors using culture medium containing $0.4 \mathrm{~g} / \mathrm{L} \mathrm{NO}^{-}{ }_{3}$ and $0.034 \mathrm{~g} / \mathrm{L} \cdot \mathrm{PO}_{4}{ }^{-3}$. Fish trials with Atlantic Salmon demonstrated that the inclusion of produced biomass into fed increase the final weight up to $5 \%$, thus confirming the adequacy of the biomass produced for aquaculture uses. The growth model and the scaling-up strategy proposed here are necessary to develop real industrial-scale processes capable of supplying microalgal biomass to the aquaculture markets, which in turn require a guaranteed supply and quality of the raw materials provided.
\end{abstract}

KEYWORDS

aquaculture, biochemical composition, flat-panel photobioreactor, light efficiency,

Nannochloropsis gaditana

\section{1 | INTRODUCTION}

Microalgae are unicellular organisms that vary in size and shape. They exist in almost all known habitats. Due to their unique biochemical composition, microalgae are exploited for a variety of applications ranging from pharmaceuticals and nutraceuticals to human food and feed, especially for aquaculture (Spolaore, Joannis-Cassan, Duran, \& Isambert, 2006). Traditionally, microalgae production in aquaculture represents one of the main problems in the development of a number of processes; this is due to the typically low productivity and poor quality of the resulting biomass along with contamination and high production costs (Muller-Feuga, 2000).
Moreover, replacement of fish meal and fish oil by microalgae biomass has been largely reclaimed as alternative to actual sources that are reaching its maximal production capacity, whereas aquaculture demand continuously increase (Lem, Bjorndal \& Lappo, 2014). However, the inclusion of microalgae in aquafeed for fish or crustaceans is still at early stage of development, mainly because the availability of, cheap but with enough quality, microalgae biomass is low and optimal strategies to include it into aquafeed is not fully developed. Different species of microalgae have been tested in fish and crustacean aquafeed, mainly for enhancement of immune system rather than as alternative to conventional raw materials (Canavate, 2017). Whatever the final application, industrial microalgae production 
requires the design and development of adequate production processes - from strain and culture medium selection to the design of suitable photobioreactors and downstream processing, which always have to be in accordance with industrial standards and regulations (Fernández-Sevilla, Acién Fernández \& Molina Grima, 2010).

Microalgae with high productivities are desirable for any application in which the biomass composition and growth rate, coupled with the organism's metabolic efficiency and robustness, are relevant selection parameters (Chisti, 2013; Wijffels \& Barbosa, 2010). Nannochloropsis gaditana is one of well-known strains and has been proposed as a source for valuable pigments and lipids, especially in aquaculture (Camacho et al., 2014; Huertas, 2000). Once a strain has been selected, the composition of the culture medium is one of the main factors affecting the strain's performance. Microalgal growth rates and biochemical composition are reported to be affected by nutrient availability, mainly $\mathrm{N}$ and $\mathrm{P}$, as well as other culture conditions such as light, temperature and the dilution rate imposed (Araujo, Matos, Gonçalves, Fernandes, \& Farias, 2011; Huang, Yao, Liu, \& Yang, 2012). Nitrogen limitation is considered the most efficient strategy to increase the content of neutral lipids in microalgae, particularly triglycerides composed of fatty acids that have a high degree of saturation (Rodolfi et al., 2009; San Pedro, González-López, Acién, \& Molina-Grima, 2014, 2015). Similar responses are induced by phosphorus, sulphur and silicon deficiency, the effect of the latter being specific to diatoms. In addition, iron availability influences the oil content although the mechanism is unknown. However, the response of microalgae to nutrient restriction varies and a general trend cannot be established among different microalgal species (Gouveia \& Oliveira, 2009; Hu et al., 2008; Huntley \& Redalje, 2007; Li, Du \& Liu, 2008; Rodolfi et al., 2009).

Regarding the production system, to carry out microalgae production on a large scale it is essential to select the most suitable photobioreactor type. For this, different parameters must be considered depending on the microorganism selected, such as (1) its optimal growth conditions and resistance to variations in environmental conditions, and (2) economic parameters such as the value of the product, the required investment and the unitary operation costs (Acién, Fernandez, Magan, \& Molina, 2012; Norsker, Barbosa, Vermuë, \& Wijffels, 2011). Thus, the objective is to achieve high productivity at minimal costs. The most common systems are open raceway reactors (Oswald \& Golueke, 1968), although tubular photobioreactors (Molina, Fernández, Acién, \& Chisti, 2001; Torzillo, Zittelli \& Chini Zittelli, 2015) and open thin-layer reactors (Doucha \& Lívanský, 1995) are today being exploited commercially in addition to the flat-panel photobioreactors that are widely utilized in aquaculture (Chini, Rodolfi, Biondi, \& Tredici, 2006; Tredici et al., 2015). Furthermore, irrespective of the reactor, there are various possible operating modes, the most common being batch mode; although by definition, productivity in continuous mode is greater than in batch mode.

In this work, we have developed a process for the outdoor production of microalgae as feed for aquaculture. First, we selected the strain and culture medium, optimized using mineral salts instead of pure chemicals. Following this, we optimized the productivity in continuous culture experiments, and modelled the influence of light availability on the growth rate as a prior step to scaling-up the production to outdoor conditions. Finally, the real outdoor photobioreactor performance was validated, evaluating the composition of the produced biomass and its suitability as feed in aquaculture. For this, fish trails were performed replacing fish oil by $5 \%$ of microalgae biomass into the fed. These steps are mandatory for the scaling-up of any microalgae production process and actual use in the aquaculture industry.

\section{MATERIALS AND METHODS}

\section{1 | Microorganism and culture conditions}

Marine microalga N. gaditana Lubián CCMP 527 was selected for this work because of its high growth rate and productivity under outdoor conditions. It was maintained under controlled conditions in $250 \mathrm{ml}$ flasks, at $20^{\circ} \mathrm{C}$, under constant illumination at $200 \mu \mathrm{E} \mathrm{m}^{-2} \mathrm{~s}^{-1}$ provided by fluorescent lamps, with constant aeration at $0.1 \mathrm{v} / \mathrm{v} / \mathrm{min}$ with no $\mathrm{CO}_{2}$ supply, in " $\mathrm{f} / 2$ " culture medium. The culture medium was prepared using nutrients of analytical grade and natural seawater, it being autoclaved at $121^{\circ} \mathrm{C}$ for $15 \mathrm{~min}$. The inoculum was subcultured every 10 days, taking $10 \%$ of the old culture and adding $90 \%$ of fresh culture medium. The inoculum cultures were monitored by microscopic observation on a Leica CME microscope 40X/0.65 to verify noncontamination problems. The inoculum was scaled up to $1 \mathrm{~L}$ using spherical flasks under the same conditions.

\section{2 | Influence of culture medium}

Three different culture media were tested: " $f / 2$ " as the control medium and two modified media "UMA3" and "UMA5", developed at the Applied Microbiology Unit of the University of Antofagasta (Chile); these were prepared using inorganics fertilizers instead of pure chemicals. The culture media composition used is shown in Table 1. Major difference between the culture media tested concern the nitrogen and phosphorous concentration as major nutrients requested to produce microalgae. To compare the performance of $N$. gaditana using these culture media, experiments were conducted at laboratory scale under controlled conditions in bubble-column reactors $(0.25 \mathrm{~m}$ in diameter and $0.25 \mathrm{~m}$ in height; height/diameter ratio $=1$ ), with a $10 \mathrm{~L}$ volume of culture. These reactors were artificially illuminated at $200 \mu \mathrm{E} \mathrm{m}^{-2} \mathrm{~s}^{-1}$ using a light/dark cycle (12:12 hr) with fluorescent lamps (Philips Master TL5 HO) and maintained at $20^{\circ} \mathrm{C}$ with a constant aeration of $0.2 \mathrm{v} / \mathrm{v} / \mathrm{min}$ and a $\mathrm{pH}=8.0$ via ondemand $\mathrm{CO}_{2}$ injection. In each test, the reactors were filled with the appropriate volume of autoclaved culture medium and inoculum until a cell density of $1 \times 10^{5} \mathrm{cel} / \mathrm{ml}^{1}$ was reached. Following this, the reactors were operated in batch mode until the stationary phase was reached, after which the reactors were operated in continuous mode until stationary state was reached, at 0.15 and 0.20 per day respectively. 
TABLE 1 Composition of different culture media used for the production of Nannochloropsis gaditana at laboratory scale

\begin{tabular}{llcrr} 
Nutrients & & f/2 Control & UMA 3 & UMA 5 \\
Macronutrients, & $\mathrm{NaNO}_{3}$ & 0.005 & 0.300 & 0.400 \\
$\mathrm{~g} / \mathrm{L}$ & $\mathrm{NaH}_{2} \mathrm{PO}_{4}$ & 0.001 & 0.034 & 0.034 \\
& $\mathrm{NaHCO}_{3}$ & 0.000 & 0.168 & 0.168 \\
\hline Trace elements, & $\mathrm{Zn}$ & 0.080 & 0.080 & 0.080 \\
$\mu \mathrm{mol} / \mathrm{L}$ & $\mathrm{Mn}$ & 0.900 & 0.900 & 0.900 \\
& $\mathrm{Mo}$ & 0.030 & 0.030 & 0.030 \\
& $\mathrm{Co}$ & 0.050 & 0.050 & 0.050 \\
& $\mathrm{Fe}$ & 11.700 & 11.700 & 11.700 \\
\hline
\end{tabular}

\section{3 | Influence of dilution rate}

To determine the optimal dilution rate, continuous culture experiments were performed in bubble-column-type reactors $(0.20 \mathrm{~m}$ in diameter and $1.0 \mathrm{~m}$ in height; height/diameter ratio $=5$ ) with a $25 \mathrm{~L}$ culture volume (Figure 1). These reactors were artificially illuminated at $130 \mu \mathrm{E} \mathrm{m}^{-2} \mathrm{~s}^{-1}$ with a light/dark cycle of $12: 12 \mathrm{hr}$ with fluorescent lamps (Philips Master TL5 HO); the cultures were maintained at $20^{\circ} \mathrm{C}$ with a constant aeration of $0.2 \mathrm{v} / \mathrm{v} / \mathrm{min}$ and $\mathrm{pH}=8.0$ via ondemand $\mathrm{CO}_{2}$ injection. In these experiments, only UMA3 culture medium was used because it was determined as optimal in previous assays. Each reactor was inoculated with $20 \%$ of its volume, reaching an initial density of $4 \times 10^{5} \mathrm{cell} / \mathrm{ml}$, cell count was performed using a Neubauer chamber under the light microscope field. It was operated in batch mode for 5 days, next the reactor was operated in continuous mode to reach steady state. Each reactor was operated at a dilution rate of $0.10,0.20,0.30$ and 0.40 per day. Each dilution rate was evaluated in duplicate.

\subsection{Validation of results under outdoor conditions}

Once the culture medium and the optimal dilution rate were determined, these results were validated outdoors under real operating conditions. The flat-panel reactors used were $0.2 \mathrm{~m}$ wide, $1.0 \mathrm{~m}$ long and $2.0 \mathrm{~m}$ high with a total volume of $400 \mathrm{~L}$ (height/diameter ratio $=10)$ (Figure 1$)$. Three reactors of this type were used, each one consisting of a bag of this size placed inside a supporting galvanized iron mesh of the same dimensions. Each bag had an aeration pipe at the base through which air was continuously supplied at $0.2 \mathrm{v} / \mathrm{v} / \mathrm{min}$. The bags were placed inside a greenhouse for protection and they were naturally illuminated by solar radiation. The culture temperature was not controlled but it ranges from 18 to $25^{\circ} \mathrm{C}$, whereas $\mathrm{CO}_{2}$ was supplied on-demand to control the $\mathrm{pH}$ at 8.0. At the beginning of each test, the culture medium was prepared and sterilized with chlorine/thiosulphate and then supplied to the reactor in addition to $20 \%$ of inoculum from the $25 \mathrm{~L}$ reactors operated under laboratory conditions. The reactor was firstly operated in batch mode then, once the stationary phase was reached, it was operated in continuous mode at the dilution rate previously determined as optimal under laboratory conditions.

\subsection{Analytical methods}

The biomass concentration into the cultures was determined daily by determining the total suspended solids by vacuum filtration of $200 \mathrm{ml}$ of the culture in 1 micron pore size filters; it was subsequently dried in an oven at $105^{\circ} \mathrm{C}$ for two hours. Furthermore, chlorophyll fluorescence ( $\mathrm{Fv} / \mathrm{Fm})$ was determined as an indicator of the photosynthetic apparatus using a AquaPen AP meter (Photon Systems Instruments, spol. s.o., Drasov, Czech Republic). Regarding the biochemical composition, the protein content of the biomass was determined using the Lowry's spectrophotometric method (1951) based on Folin reagent. Total lipids were determined by the Kochert gravimetric method (1992) using methanol chloroform as the extracting solvent. Ashes content was determined by calcination at $650^{\circ} \mathrm{C}$ in oven. The carbohydrate content was determined from the difference after determining the lipid, protein and ash contents.

\subsection{Light properties and average irradiance}

The optical properties of the biomass were measured in a Dynamica DB-20 spectrophotometer. For this, a glass cuvette (1 cm deep) was filled with culture and absorbance was measured at wavelengths ranging from 400 to $700 \mathrm{~nm}$. These measurements were carried out directly on the culture within a few seconds, with no pre-treatment or operation, such as centrifugation, extraction, etc. The extinction coefficient of the biomass (Ka, $\mathrm{m}^{2} / \mathrm{g}$ ) was calculated by dividing the average absorption by the biomass concentration $(\mathrm{Cb}, \mathrm{kg} / \mathrm{m})$ and the cuvette's light path $(p, m)$ (Equation [1]).
FIGURE 1 Images of the culture systems used in our experiments. Left: the bubble-column reactors used at laboratory scale; Right: the flat-panel reactors used outdoors [Colour figure can be viewed at wileyonlinelibrary.com]
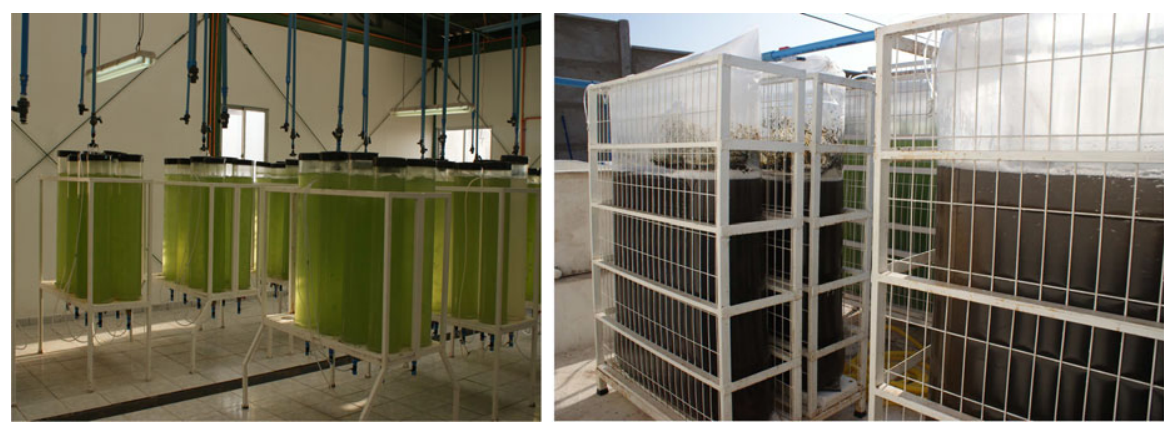


$$
\mathrm{Ka}=\frac{\mathrm{Abs}}{(p * C b)}
$$

The average irradiance in the photosynthetically active radiation range (PAR) at which cells are exposed inside a culture (lav, $\mu \mathrm{E} \mathrm{m}^{-2} \mathrm{~s}^{-1}$ ) is a function of the irradiance in the absence of cells (lo), the biomass extinction coefficient $\left(\mathrm{Ka}, \mathrm{m}^{2} / \mathrm{g}\right.$ ), the biomass concentration $(\mathrm{Cb}, \mathrm{kg} / \mathrm{m})$ and the light path inside the reactor $(p, m)$, which is calculated by (Equation [2]) (Molina Grima, Garcia Camacho, Sanchez Perez, Acien Fernandez, \& Fernandez Sevilla, 1997):

$$
\operatorname{lav}=\frac{\mathrm{lo}}{(\mathrm{Ka} * \mathrm{p} * \mathrm{Cb})} *\left(1-e^{-\mathrm{Ka} * \mathrm{p} * \mathrm{Cb}}\right)
$$

\section{7 | Fish trials including Nannochloropsis gaditana biomass}

Fish trials were carried out with the produced biomass by replacing fish oil by Nannochloropsis gaditana biomass into the diet. For this, 202 adults of Atlantic salmon (Salmo salar) were selected and collected in a pond of $7 \mathrm{~m}^{3}$ during 19 days. At the end of this period, 140 fish were distributed in four ponds of $1 \mathrm{~m}^{3}$ with 35 fish/tank to be adapted for 16 days. Subsequent to this stage the feeding process was started for 49 days with 2 diets, one control and the control diet $+5 \%$ microalga (Diet A) (Table 2). The manufacture of the fed (Control and Diet A) was performed by the Center of Studies of the University of Santiago (CEUS-Llanquihue). For this, $20 \mathrm{~kg}$ of the Aquavet 250 diet (Biomar, Chile) were grinded to, obtain the premixture of the aquafeed to manufacture the control diet and diet A. For the manufacture of the control diet, portions of all the grindings were taken; in the case of diet A, $5 \%$ of microalgae powder was added to the mills, homogenizing and then proceeding to extrude at $87^{\circ} \mathrm{C}$ and 10.2 bar, obtaining the pellets of $6 \mathrm{~mm}$. At the end of the

TABLE 2 Proximal composition of fed used during the fish trials (Control and Diet A incorporating 5\% of Nannochloropsis gaditana biomass)

\begin{tabular}{|llcc}
\hline \multirow{2}{*}{ Control } & Analysis & $\begin{array}{c}\text { Results }(\mathrm{g} / 100 \mathrm{~g} \\
\text { sample) }\end{array}$ & $\begin{array}{c}\text { Relative } \\
\text { variation }\end{array}$ \\
& Humidity & 6.2 & \\
& Proteins & 31.7 & \\
& Lipids & 24.3 & \\
& Ashes & 9.0 & \\
& Raw fibre & 2.9 & \\
Diet A & Non-nitrogenous extract & 20.5 & \\
& Energy (Kcal/100 g) & 449 & $134 \%$ \\
& Humidity & 8.3 & $111 \%$ \\
& Proteins & 35.2 & $103 \%$ \\
& Lipids & 25.0 & $117 \%$ \\
& Ashes & 10.5 & $86 \%$ \\
& Raw fibre & 2.5 & $90 \%$ \\
& Non-nitrogenous extract & 18.5 & $98 \%$ \\
& Energy (Kcal/100 g) & 440 & \\
\hline
\end{tabular}

extrusion process, the pellets were distributed in trays to be dried in an oven for $20 \mathrm{~min}$ at $950^{\circ} \mathrm{C}$, finally the diets were mixed with $22 \%$ of a 50/50 mixture of fish oil and oil of canola. However, at the time of accepting $\operatorname{diet} A$, it was observed that the pellet were not able to absorb the percentage of oil incorporated, therefore, it was allowed to drain and by difference of weight was determined once the diet had been left with $16 \%$ of accepted. Then, at the time of accepting the control diet was supplied with $16 \%$ with a mixture of $50 / 50$ fish oil and canola. Standard Feed Rate (\%SFR) at the end of the acclimation phase, the two diets (control and A) were started for 49 days, maintaining a SFR of $1.3 \%$ on the first day, the second day increasing to $1.6 \%$ of the SFR due to the good behaviour of feeding of fish. At 22 days was increased to $1.8 \%$ of SFR to stimulate the increase in fish consumption, this percentage of SFR was maintained during the rest of the period. The feed was provided manually according to the demand of the fish, stopping the delivery of feed when the fish had no response to feeding. Four doses were given in the morning from $9: 30$ to $12: 00$ and three doses in the afternoon from 14:30 to 16:00.

After completing the feeding phase with the experimental diets, the zootechnical factors were determined. These include the conversion factor (FCR) which indicates the amount of feed required per $\mathrm{kg}$ of fish produced [Equation [3]]. The growth in weight as percentage, where W2 is the final weight and W1 is the initial weight of the fish (Equation [4]). The standard growth rate (SGR), as the logarithmic increase in weight to days of experiment (D) ratio, which defines the degree of growth of the species (Equation [5]). The coefficient of thermal growth (TGC), that considers the temperature of the water $\left(t,{ }^{\circ} \mathrm{C}\right)$ and the days of feeding (D) (Equation [6]). The condition factor $(K)$, which indicates the nutritional state of the organisms (state of thinness or fat) (Equation [7]).

$$
\begin{aligned}
\mathrm{FCR} & =\frac{\text { Food delivered }}{\text { Increase in weight }} \\
\text { Growth in weight }(\%) & =\frac{(\mathrm{W} 2-\mathrm{W} 1)}{\mathrm{W} 1} \times 100 \\
\mathrm{SGR}(\%) & =\frac{(\ln W 2-\ln \mathrm{W} 1)}{D} \times 100 \\
\mathrm{TGC} & =\frac{\left(\mathrm{W} 2^{1 / 3}-W 1^{1 / 3}\right.}{\sum t \cdot D} \times 100 \\
K & =\frac{W_{\text {eight }}}{\text { Length }^{3}} \times 100
\end{aligned}
$$

The proximal analysis of the fish were performed according to the Chilean standard NCh 841 Of 78 and the profile of fatty acids in muscle were analysed according to AOAC 963 (1995), these analyses were executed by the Center for Studies in Science and Food Technology (CECTA) of the University of Santiago, Chile. Samples were taken at the beginning of the experiment, called basal samples, which was carried out in parallel to the sampling and distribution of the experiment, where samples were taken for proximal analysis (10 fish) and fatty acid profile (five fish) in carcass and muscle. Finally, the sampling of the ponds corresponding to the "Control" and "Diet 
A" were carried out, under the same regulations in the aforementioned study centre.

The results of the zootechnical factors are expressed as averages \pm the standard error of each of the replicates per treatment. The results of the proximal and fatty acid analysis are expressed as the average of the pool samples for basal sampling, and the pool samples of each of the samples analysed by replicate. The data obtained in the feeding stage and samples were analysed using a Shapiro-Wilk normality test, those data that $p>.05$ were assumed to be normal, those data that $p<.05$ did not have a normal distribution of the data. For the data that demonstrated a normal distribution, ANOVA was performed using the Tukey Test. Those data that did not show a normal distribution were applied nonparametric Kruskall-Wallis test. The level of significance was assumed to be $>95 \%$ $(p<.05)$. Statistical analysis was performed using the Infostat program, version 20131.

\section{3 | RESULTS AND DISCUSSION}

Among the different microalgae strains used in aquaculture $N$. gaditana is one of most extensively cultivated due to its high content of polyunsaturated fatty acids, high productivity and robustness in outdoor conditions (Camacho et al., 2014; Rodolfi et al., 2009). To put in order a process for its outdoor production for aquaculture purposes, the first step is to select the most suitable culture medium. Three different culture mediums were tested. One was $f / 2$ culture medium, which is widely recommended at laboratory scale, and the other two, UMA3 and UMA5, were formulated using mineral salts instead of pure chemicals (Table 1 ). The performance of $N$. gaditana batch cultures grown in these culture media under controlled laboratory conditions is summarized in Figure 2. Results show that the biomass concentration at the end of the batch culture was higher, up to $0.6 \mathrm{~g} / \mathrm{L}$, when using UMA5 culture medium than using $f / 2$ and UMA3 culture media, for which the maximal biomass concentration was $0.4 \mathrm{~g} / \mathrm{L}$. In terms of productivity, this was also higher using UMA5 culture medium, with a maximal value of $0.06 \mathrm{~g} \mathrm{~L}^{-1}$ day $^{-1}$ being obtained at a biomass concentration of $0.4 \mathrm{~g} / \mathrm{L} \cdot$ on day 6 of the culture when the growth rate was 0.15 per day. Under the same light conditions, a higher biomass concentration was not obtained by providing more nitrogen; thus $0.52 \mathrm{~g} / \mathrm{L}$ of biomass was achieved in batch cultures of N. gaditana illuminated at $250 \mu \mathrm{E} \mathrm{m}^{-2} \mathrm{~s}^{-1}$ when providing $1.13 \mathrm{~g} / \mathrm{L}$.of potassium nitrate (Camacho-Rodríguez, Cerón-García, Fernández-Sevilla, \& Molina-Grima, 2015). In contrast, providing a similar concentration of nitrate, up to $0.7 \mathrm{~g} / \mathrm{L}$ of potassium nitrate, the biomass productivity was higher, up to $0.1 \mathrm{~g} \mathrm{~L}^{-1} \mathrm{day}^{-1}$, when providing much more irradiance, up to $1000 \mu \mathrm{E} \mathrm{m}^{-2} \mathrm{~s}^{-1}$. This confirms that the nitrogen requirement is a direct function of the light provided, which finally determines the biomass productivity (González-López et al., 2013).

The growth rate data confirm that growth was higher when using UMA3 and UMA5 culture media. Maximal values, ranging from 0.35 to 0.38 per day, were obtained during the first days of the experiment when the biomass concentration was lower and the light
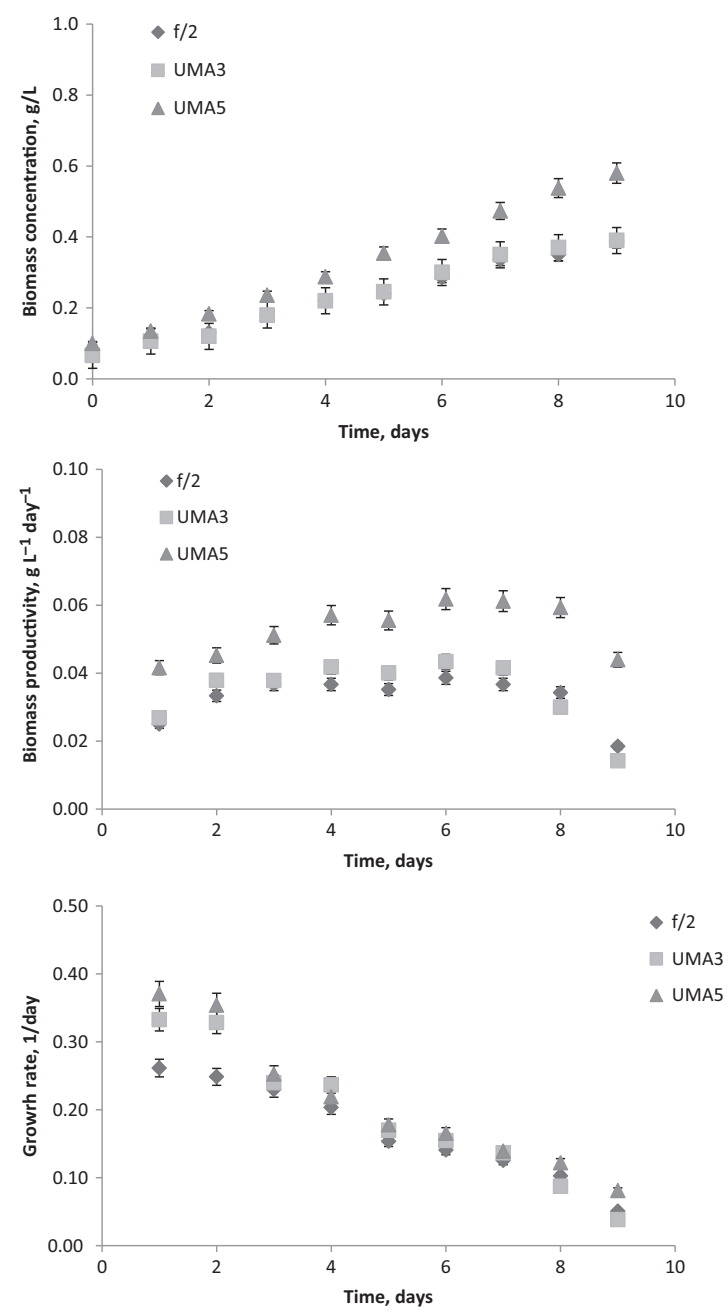

FIGURE 2 Influence of the culture medium on the biomass concentration, productivity and growth rate of Nannochloropsis gaditana batch cultures performed at $200 \mu \mathrm{E} \mathrm{m}^{-2} \mathrm{~s}^{-1}$ in $10 \mathrm{~L}$ reactors

availability was higher. These values agree with those previously reported, of 0.31-0.35 per day, including under outdoor conditions in tubular photobioreactors with high light availability and no nutrient limitation (San Pedro et al., 2015). These data confirm that UMA5 is a suitable culture medium to produce N. gaditana as it contains the adequate concentration and proportion of nutrients. When using $f / 2$ culture medium, the nitrogen concentration is too low $(0.06 \mathrm{mM})$ whereas using UMA3 culture medium, the ratio between nitrogen and phosphorus seems to be insufficient (N/P = 8). Phytoplankton on average requires $\mathrm{C}, \mathrm{N}$ and $\mathrm{P}$ in an approximate molar ratio of 106:16:1, the Redfield ratio (Geider \& Roche 2002). On this way, the N:P ratio is a value allowing to know the nutritional status of phytoplankton, values higher than 20 indicate a phosphorus deficiency while values below 10 indicates nitrogen deficiency. In laboratory cultures, optimal molar $\mathrm{N}: \mathrm{P}$ ratios measured for different phytoplankton species lie in the range between 7 and 84 (Lagus, 2009). The nitrogen concentration and nitrogen to phosphorus ratio are widely recognized as major factors in determining the performance of microalgae growth and composition (González, Tabernero, 
Sánchez, Martin del Valle, \& Galán, 2014; Sepúlveda et al., 2015). In any case, the adequacy of the culture medium must be validated in continuous mode when the cultures' maximal performance can be obtained, and the maximal nutrient requirements take place. Culture medium optimization is a major bottleneck for the large-scale production of microalgae because of the high cost and large amount of nutrients required. To reduce the biomass production cost, the utilization of low cost nutrients is mandatory (Acién et al., 2012). It is for this reason that the high costs traditionally associated with microalgae production discouraged the commercial development of microalgae-based fish factories (Jaime-Ceballos, Hernández-Llamas, Garcia-Galano, \& Villarreal, 2006). In addition, with N. gaditana, the optimization of the culture medium composition allows one to maximize the biomass productivity and valuable products content (Breuer, Lamers, Martens, Draaisma, \& Wijffels, 2012; Griffiths, van Hille \& Harrison, 2012).

As a previous step to performing experiments in continuous mode, the growth of $N$. gaditana was modelled as a function of light availability; to do this, the biomass extinction coefficient and the average irradiance inside the cultures were determined. The extinction coefficient of the biomass was determined spectrophotometrically, allowing a determination of the cells' light attenuation. Results show that this parameter changed with the different culture media used, the lowest value, of $0.139 \mathrm{~m}^{2} / \mathrm{g}$, was obtained when utilizing UMA5 culture medium whereas, when using $f / 2$ and UMA3, the extinction coefficients were 0.167 and $0.185 \mathrm{~m}^{2} / \mathrm{g}$ respectively (Tabla 4). Similar extinction coefficient values, ranging from 0.129 to $0.175 \mathrm{~m}^{2} / \mathrm{g}$, have been reported elsewhere for this strain (Huang et al., 2012). Moreover, it was previously reported that the extinction coefficient of $N$. gaditana ranged from 0.19 to $0.21 \mathrm{~m}^{2} / \mathrm{g}$ when the irradiance was modified from 300 to $500 \mu \mathrm{E} \mathrm{m}^{-2} \mathrm{~s}^{-1}$, or from 0.18 to $0.22 \mathrm{~m}^{2} / \mathrm{g}$ when changing the culture medium composition from Algal culture medium to centrate (Sepúlveda et al., 2015). The lowest biomass extinction coefficient when using UMA5 culture medium means that, for the same biomass concentration and light conditions, more light is available for the cells inside the culture; hence, it is possible to achieve a higher growth rate and higher productivity.

Using the concept of average irradiance to quantify light availability inside the culture, the variation in the growth rate as a function average irradiance at which the cells are exposed to inside the culture, for the three culture media assayed, was determined (Figure 3). Results confirm that the growth rate hyperbolically increases with the average irradiance inside the culture; for the same average irradiance, the growth rate is higher when using UMA5 culture medium than for the UMA3 or $\mathrm{f} / 2$ culture media. The experimental data were fitted to the hyperbolic model previously reported (Grima et al., 1996) (Equation [1]), obtaining the value of characteristic parameters of the model (Table 3).

$$
\mu=\frac{\mu_{\max } \cdot \operatorname{lav}^{n}}{\mathrm{Ik}^{n}+\operatorname{lav}^{n}}
$$

Data show that the specific maximal growth rate $\left(\mu_{\max }\right)$ was highest, up to 0.51 per day, and the irradiance constant (Ik) was

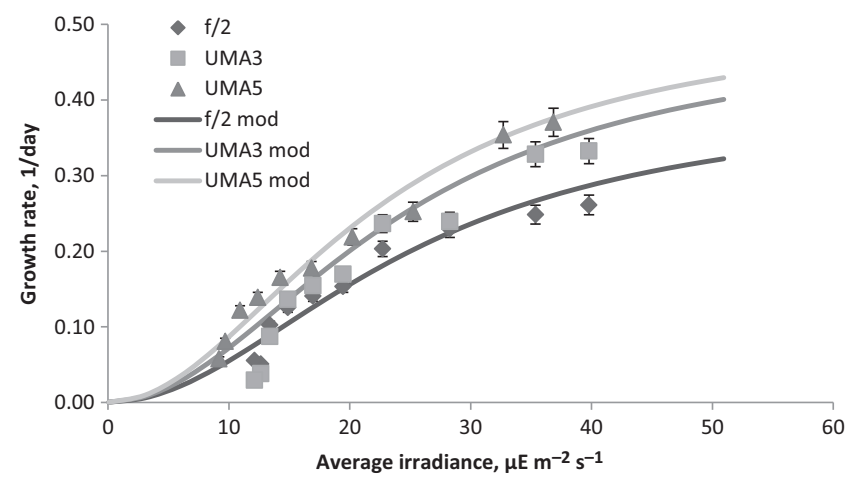

FIGURE 3 Variation in the growth rate with average irradiance for Nannochloropsis gaditana batch cultures performed at $200 \mu \mathrm{E} \mathrm{m} \mathrm{m}^{-2} \mathrm{~s}^{-1}$ in $10 \mathrm{~L}$ reactors

lowest, of $22 \mu \mathrm{E} \mathrm{m} \mathrm{m}^{-2} \mathrm{~s}^{-1}$, when using the UMA5 culture medium rather than the other culture media; this confirms the greater suitability of this culture medium for $N$. gaditana production. The worst results were obtained when using $f / 2$ culture medium, with a specific maximal growth rate of 0.40 per day and an irradiance constant of $25 \mu \mathrm{E} \mathrm{m}^{-2} \mathrm{~s}^{-1}$ being determined. These values are similar to those previously reported for this strain, including for outdoor tubular photobioreactors; namely, a specific maximal growth rate of 0.50 per day and an irradiance constant of $41 \mu \mathrm{E} \mathrm{m}^{-2} \mathrm{~s}^{-1}$ (San Pedro et al., 2015), thus validating the experimental values here determined. According to these figures, the optimal dilution rate for continuous operation of the cultures would be 0.25 per day, which corresponds to $50 \%$ of the specific maximal growth rate. Under outdoor conditions, it was previously reported that maximal productivity of $N$. gaditana cultures was achieved at 0.3 per day in flat-panel reactors (Camacho-Rodríguez et al., 2015) whereas for tubular photobioreactors, the maximal productivity was achieved at a 0.4 per day dilution rate (San Pedro et al., 2015), thus confirming that the adequacy of culture conditions inside the reactor influences the optimal performance of the cultures and at the end the optimal dilution rate.

To validate the results obtained from the batch cultures, experiments were performed in continuous mode with the three different culture media at different dilution rates - from 0.15 to 0.30 per day (Figure 4). Results confirm that biomass productivity was modified by the dilution rate imposed, with maximal values of $0.08 \mathrm{~g} \mathrm{~L}^{-1}$ day $^{-1}$ being obtained when using the optimal UMA5 culture medium and a dilution rate close to the optimal of 0.20 per day. When using the optimal UMA5 culture medium, the biomass productivity decreased both above and below the optimal dilution rate of 0.20 per day. A similar trend was observed for the other culture media assayed, the lowest values being obtained using the $f / 2$ culture medium; this is because it contains a lower nutrient concentration. By comparing the operation in batch and continuous modes, it was shown that for batch mode, the accumulated maximal biomass productivity was $0.05 \mathrm{~g} \mathrm{~L}^{-1}$ day $^{-1}$; this value reducing if including 
TABLE 3 Variation in the biomass extinction coefficient and the model of growth parameter characteristic as a function of the culture medium used in Nannochloropsis gaditana batch cultures at $200 \mu \mathrm{E} \mathrm{m}^{-2} \mathrm{~s}^{-1}$

\begin{tabular}{lccc} 
Parameter & $\mathrm{f} / 2$ & UMA3 & UMA5 \\
$\mathrm{Ka}, \mathrm{m}^{-2} \mathrm{~g}^{-1}$ & 0.167 & 0.185 & 0.139 \\
$\mu_{\max }$, per day & 0.40 & 0.49 & 0.51 \\
$\mathrm{n}$ & 2.00 & 2.00 & 2.00 \\
$\mathrm{lk}, \mu \mathrm{E} \mathrm{m} \mathrm{m}^{-2} \mathrm{~s}^{-1}$ & 25.00 & 24.00 & 22.00 \\
\hline
\end{tabular}

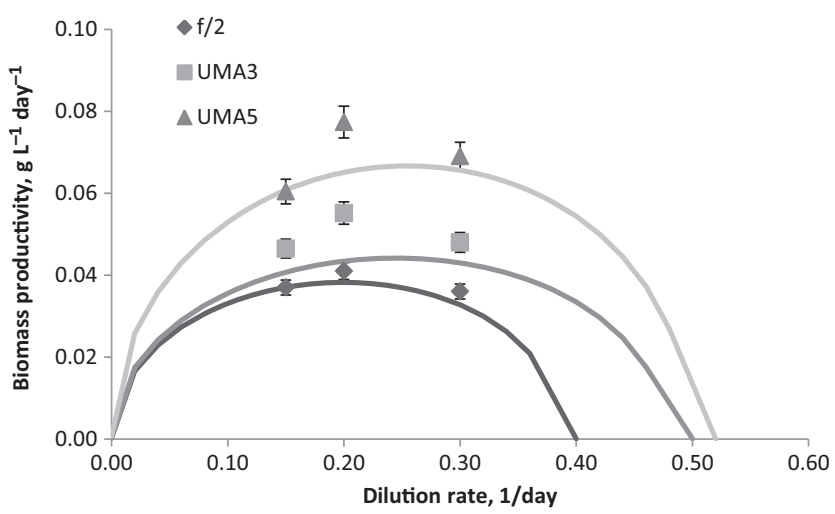

FIGURE 4 Variation in biomass productivity with the dilution rate of Nannochloropsis gaditana continuous cultures performed at $200 \mu \mathrm{E} \mathrm{m}^{-2} \mathrm{~s}^{-1}$ in $10 \mathrm{~L}$ reactors. Symbols correspond to experimental measurements, whereas lines correspond to simulated data using the growth model developed for each of the culture media tested

the requested time to restart the system after each batch culture. However, in continuous mode the biomass productivity was up to $0.08 \mathrm{~g} \mathrm{~L}^{-1} \mathrm{day}^{-1}$, thus confirming the greater performance of continuous cultures versus batch cultures for microalgae biomass production.

To validate the accuracy of the developed model, a new set of experiments was performed using thinner bubble-column photobioreactors $-0.18 \mathrm{~m}$ in diameter and $1.2 \mathrm{~m}$ in height. Both batch and continuous culture trials were carried out. Results from the batch culture show a similar trend to that previously observed (Figure 5). The biomass concentration increased from an initial value of 0.10 to $0.90 \mathrm{~g} / \mathrm{L}$ in 18 days. The maximal biomass productivity values, of $0.06 \mathrm{~g} \mathrm{~L}^{-1} \mathrm{day}^{-1}$, were measured on days 6 to 12 , with the biomass concentration ranging from 0.30 to $0.50 \mathrm{~g} / \mathrm{L}$. These values were similar to those previously obtained, indicating that the culture medium and operating conditions used were analogous. Regarding the growth rate and average irradiance, the results show that the maximal growth rate measured was 0.45 per day. This occurred when there was higher average irradiance inside the reactor, up to $50 \mu \mathrm{E} \mathrm{m}^{-2} \mathrm{~s}^{-1}$, but it reduced to 0.03 per day when the biomass concentration increased and the light availability decreased to $5 \mu \mathrm{E} \mathrm{m}^{-2} \mathrm{~s}^{-1}$ (Figure 5). Maximal biomass productivity occurred when the average irradiance ranged from 10 to $14 \mu \mathrm{E} \mathrm{m}^{-2} \mathrm{~s}^{-1}$, with the growth rate ranging from 0.14 to 0.12 per day. These figures are slightly lower than those previously obtained because the illumination reaching these reactors was likewise lower. Nonetheless, regardless of the low illumination, the system behaviour fitted that predicted by the proposed model. Thus, in Figure 6, the variation in growth rate is shown with the average irradiance that was experimentally measured during the batch culture. The results agree with those predicted by the proposed growth model for the illumination conditions used in these experiments, thus validating the developed model's adequacy. Moreover, the model was able to fit data from the continuous culture with even greater accuracy than that from the batch mode (Figure 6). Therefore, the experiments performed at dilution rates of between 0.10 and 0.40 per day confirm that UMA5 was an adequate culture medium for $N$. gaditana production, with optimal performance/maximal productivity being obtained at dilution rates ranging from 0.20 to 0.30 per day (Figure 7). With regard to the illumination and culture conditions used in these experiments, the biomass concentration achieved in this dilution rate ranged was from 0.2 to $0.3 \mathrm{~g} / \mathrm{L}$, making the biomass productivity $0.06 \mathrm{~g} \mathrm{~L}^{-1}$ day $^{-1}$; however, these values can be greater when higher irradiance is prevailing under outdoor conditions. Indeed, biomass productivities of up to $0.4 \mathrm{~g} \mathrm{~L}^{-1}$ day $^{-1}$ have been reported in outdoor $\mathrm{N}$. gaditana cultures grown in $5 \mathrm{~cm}$-wide flat-panel reactors at solar radiation levels ranging from 10 to $25 \mathrm{MJ} / \mathrm{m}^{2}$ day (460 to $\left.1100 \mu \mathrm{E} \mathrm{m}^{-2} \mathrm{~s}^{-1}\right)$ and operating at an optimal dilution rate of 0.3 per day (Camacho et al., 2014).

To validate the developed model under outdoor conditions, a batch experiment was performed under real outdoor conditions using a $0.4 \mathrm{~m}^{3}$ flat-panel reactor located inside a greenhouse in Antofagasta, Chile. Results show a similar trend to that observed under laboratory conditions (Figure 8). The biomass concentration increased from 0.18 to $0.95 \mathrm{~g} / \mathrm{L}$ in 12 days, with maximal biomass productivity values of $0.08 \mathrm{~g} \mathrm{~L}^{-1}$ day $^{-1}$ being measured on day 7 . Regarding the growth rate and average irradiance, the highest growth rate was measured on the first day, at 0.30 per day, when the highest average irradiance was available, up to $37 \mu \mathrm{E} \mathrm{m} \mathrm{m}^{-2} \mathrm{~s}^{-1}$; it then decreased to near zero when the average irradiance dropped to $7 \mu \mathrm{E} \mathrm{m}^{-2} \mathrm{~s}^{-1}$. Far greater values had been expected outdoors due to the high solar radiation at this location. However, when analysing the actual solar radiation available on the reactor surface, a value of just $225 \mu \mathrm{E} \mathrm{m}^{-2} \mathrm{~s}^{-1}$ was determined, close to values used at the laboratory scale - this explains the similar biomass productivity and growth rate measured under the experimental conditions tested. So, although solar radiation at this location reached values above $2500 \mu \mathrm{E} \mathrm{m} \mathrm{m}^{-2} \mathrm{~s}^{-1}$, the greenhouse cover reduced the solar radiation available inside the greenhouse to $1500 \mu \mathrm{E} \mathrm{m}^{-2} \mathrm{~s}^{-1}$ (a $40 \%$ attenuation). As the solar cycle only provides light for approximately $12 \mathrm{hr}$, the mean solar radiation during the daylight period goes down to $750 \mu \mathrm{E} \mathrm{m}^{-2} \mathrm{~s}^{-1}$ (a $50 \%$ distribution). Moreover, due to the vertical arrangement of the flat panels and the shadow thrown from one reactor onto another, only $30 \%$ of the solar radiation is really available at the reactor surface (San Pedro et al., 2015); thus, the final 

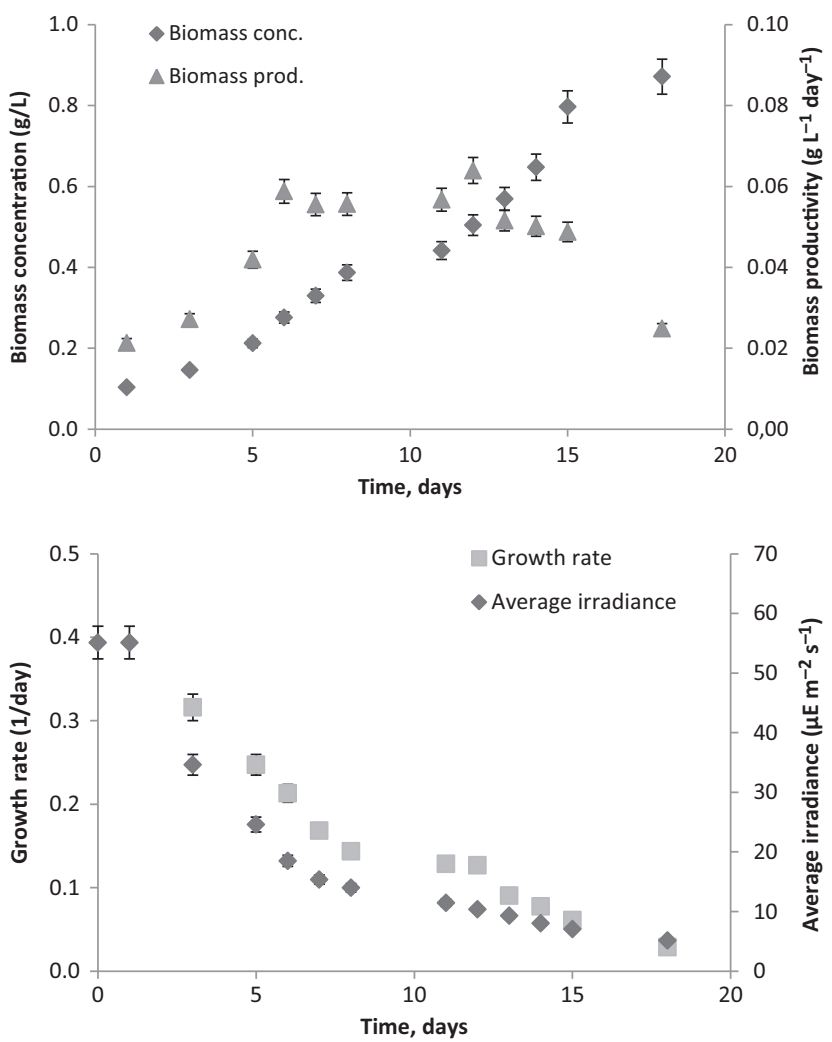

FIGURE 5 Variation in biomass concentration, productivity, growth rate and average irradiance over time of a Nannochloropsis gaditana batch culture performed at $130 \mu \mathrm{E} \mathrm{m}^{-2} \mathrm{~s}^{-1}$ in $25 \mathrm{~L}$ bubblecolumn photobioreactors

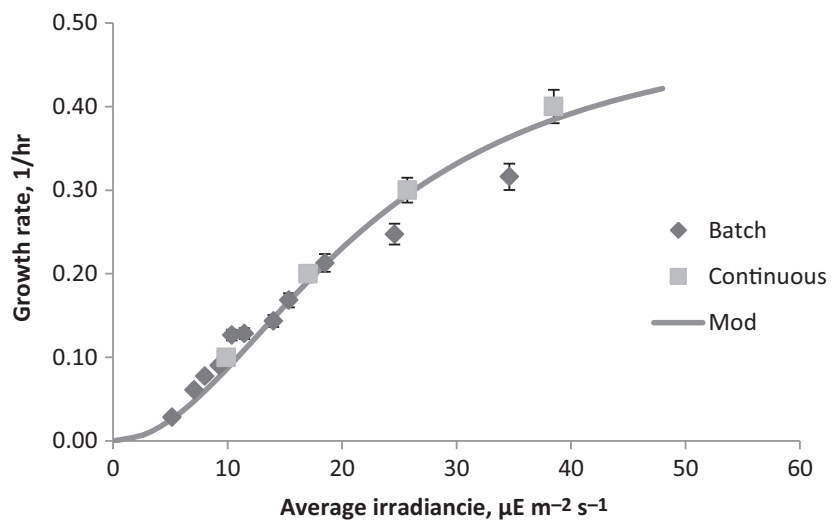

FIGURE 6 Variation in the growth rate with average irradiance of Nannochloropsis gaditana batch culture performed at $130 \mu \mathrm{E} \mathrm{m}^{-2} \mathrm{~s}^{-1}$ in $25 \mathrm{~L}$ bubble-column photobioreactors. Symbols represent experimental data obtained in batch and continuous mode, whereas the line corresponds to simulated values from the growth model developed

solar radiation availability reduces to $225 \mu \mathrm{E} \mathrm{m} \mathrm{m}^{-2} \mathrm{~s}^{-1}$. A similar pattern of light availability has previously been described in flat panels where the reactors' location and orientation had a significant influence on the final solar radiation availability (San Pedro et al., 2015). In any case, the developed model also fitted the results from flat-

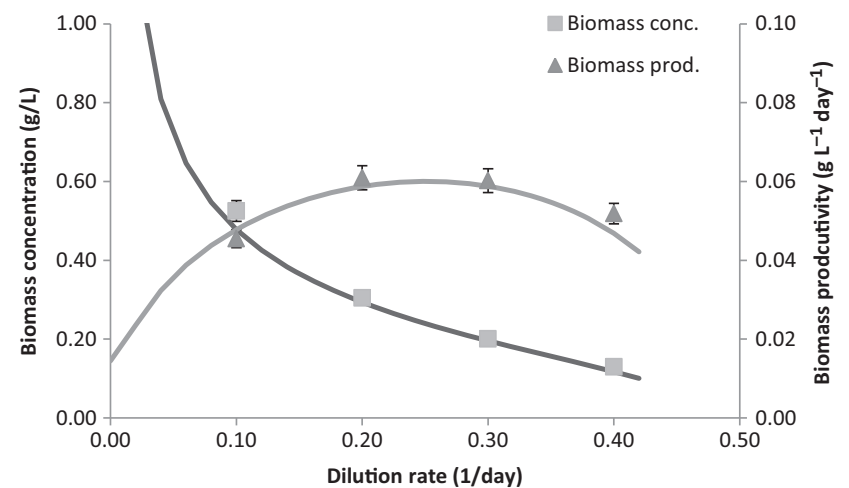

FIGURE 7 Variation in biomass concentration and productivity with the dilution rate of Nannochloropsis gaditana continuous cultures performed at $130 \mu \mathrm{E} \mathrm{m}^{-2} \mathrm{~s}^{-1}$ in $25 \mathrm{~L}$ bubble-column photobioreactors. Symbols correspond to experimental data obtained in continuous mode, whereas the line corresponds to simulated values from the growth model developed
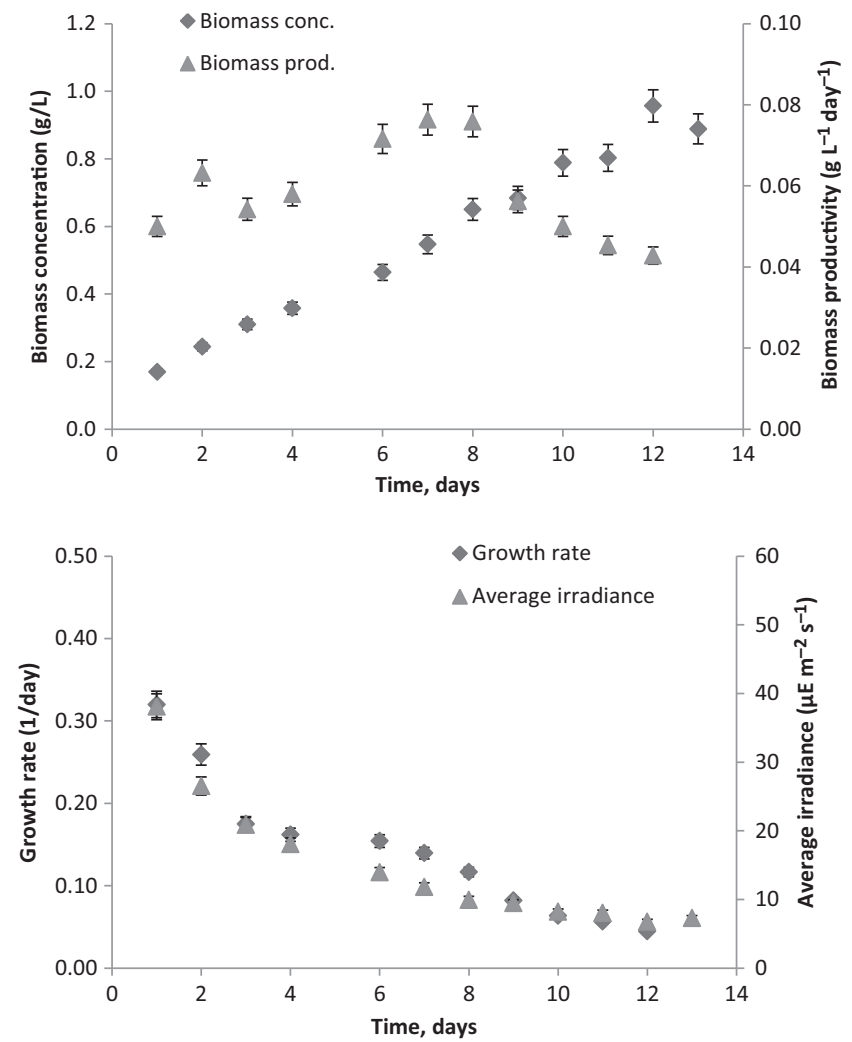

FIGURE 8 Variation in biomass concentration, productivity, growth rate and average irradiance over time of a Nannochloropsis gaditana batch culture performed in $400 \mathrm{~L}$ outdoor flat panels at Antofagasta, Chile

panel reactors, confirming the developed model's validity for use in the scaling-up of N. gaditana cultures (Figure 9). The model not only reproduced the data from the batch culture performed but also from the continuous culture, which was carried out at an optimal dilution rate of 0.25 per day and for which a maximal biomass productivity of $0.12 \mathrm{~g} \mathrm{~L}^{-1} \mathrm{day}^{-1}$ was measured. This value measured in the 


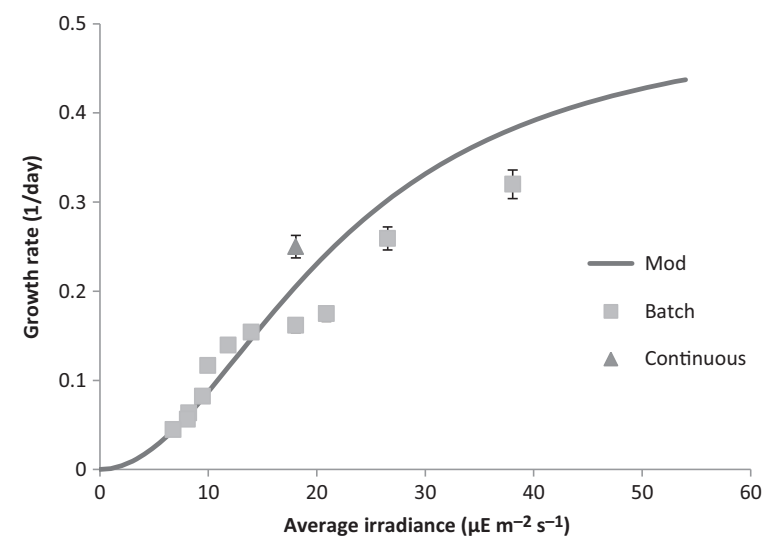

FIGURE 9 Variation in the growth rate with average irradiance of Nannochloropsis gaditana culture performed in $400 \mathrm{~L}$ outdoor flat panels at Antofagasta, Chile. Symbols represent experimental data obtained in batch and continuous mode, whereas the line corresponds to simulated data from the proposed growth model developed

continuous culture was 2.8 times higher than the accumulated biomass productivity in batch mode of $0.04 \mathrm{~g} \mathrm{~L}^{-1}$ day $^{-1}$, thus confirming the better performance of continuous culture versus batch mode. In any case, the productivity measured here in continuous mode was lower than the maximal value of $0.4 \mathrm{~g} \mathrm{~L}^{-1} \mathrm{day}^{-1}$ achieved in 5-cm-wide flat panels (Camacho et al., 2014) because of the wider flat panels used in this research $(20 \mathrm{~cm})$. The data obtained here agree with that previously reported, which ranged from $1.5 \mathrm{~g} \mathrm{~L}^{-1} \mathrm{day}^{-1}$ for $1 \mathrm{~cm}$-wide flat panels to $0.2 \mathrm{~g} \mathrm{~L}^{-1} \mathrm{day}^{-1}$ for $17 \mathrm{~cm}$-wide flat panels, equivalent to areal productivities ranging from 11 to $22 \mathrm{~g} \mathrm{~m}^{-2} \mathrm{day}^{-1}$ (Zou \& Richmond, 1999). Moreover, when considering a distance between the reactors equal to the total height of the reactors, the estimated areal productivity was $21 \mathrm{~g} \mathrm{~m}^{-2} \mathrm{day}^{-1}$. This value was only measured for a short period but it was higher than the mean annual productivity of $15 \mathrm{~g} \mathrm{~m}^{-2}$ day $^{-1}$ (36 tn ha ${ }^{-1}$ year $^{-1}$ ) reported for a 1-ha facility of flat panels (Tredici et al., 2015).

When performing an economic analysis for the production of 1 ton of microalgas biomass, it was concluded that fertilizers summarizes $5.1 \%$ and $4.8 \%$ of the final production cost when using UMA3 and UMA5 culture media respectively. In spite of the higher nutrients concentration of UMA5, the higher biomass productivity achieved when using this culture medium allows to reduce the biomass production cost when using it. It is in agreement with previously reported values summarizing that fertilizers represent up to $54 \%$ of raw material cost, in addition to pure $\mathrm{CO} 2$, which represents up to $39 \%$. Regarding raw materials, the fertilizer cost cannot be reduced, so the only possibility is to reduce their consumption per biomass mass unit produced (Acién, Molina, Fernández-Sevilla, Barbosa, \& Gouveia, 2017). Finally, the biomass quality was evaluated not only by determining its biochemical composition but also by performing fish trials. Analysis of the biomass shows that carbohydrates make up the major biomass fraction, followed by proteins and lipids (Figure 10). The protein and lipid content is high, at $24 \%$ and $22 \%$,

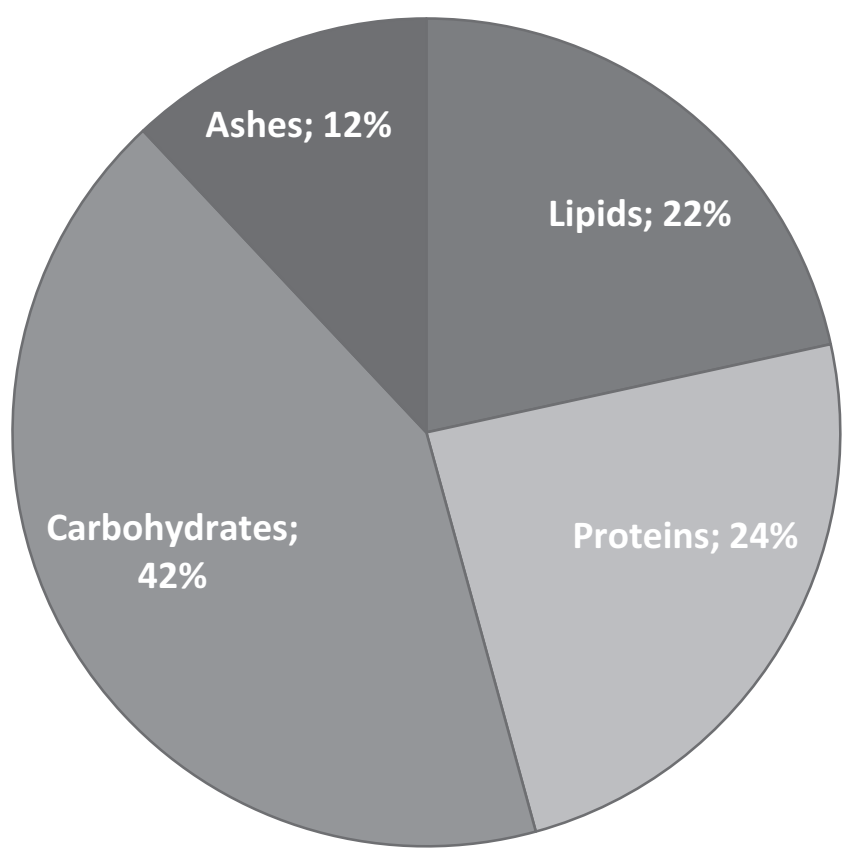

FIGURE 10 Biochemical composition of Nannochloropsis gaditana biomass produced at 0.25 per day in $400 \mathrm{~L}$ outdoor flat panels at Antofagasta, Chile

respectively, making it a raw material of interest for feeding animals in aquaculture. The biochemical composition determined is similar to that reported from outdoor cultures in flat-panel and tubular photobioreactors. In both cases, the protein content ranged from $30 \%$ to $40 \%$ d.wt., whereas the carbohydrate content ranged from $20 \%$ to $30 \%$ d.wt. and the lipid content from 20\% to 30\%d.wt. (Camacho et al., 2014; San Pedro et al., 2014, 2015).

Furthermore, because lipids from N. gaditana typically contain high levels of polyunsaturated fatty acids, $N$. gaditana has been extensively used not only for feeding larvae but also a small proportion of this biomass is also included in pellets for feeding juveniles, $N$. gaditana definitely show potential as an alternative for fish oil since the amount to be consumed is feasible (Ryckebosch et al., 2014).

In this work, flat panels were employed to produce $45 \mathrm{~kg}$ of dry biomass that was used to prepare fed containing $5 \%$ of $N$. gaditana biomass as substitute of fish oil. The composition of "Control" and "Diet A" feed is showed in Table 2. Experiments were performed feeding Atlantic salmon (Salmon salar) during 49 days, the zootechnical factors at the end of the experiments being evaluated (Table 4). Results show as the inclusion of biomass of N. gaditana into "Diet A" has a positive effect in the growth and performance of Atlantic salmon. Thus, the final weight was $5 \%$ higher when using Diet $A$ than in control, the standard growth rate being up to $12 \%$ higher when using Diet $A$ than in control assay. Two additional important parameters as survival and conversion factor also increases when using fed incorporation biomass of N. gaditana, survival increasing up to $3 \%$ whereas fed conversion efficiency into biomass increase also up to $3 \%$. It can be observed that the control diet despite having obtained the lowest FCR value $(1.55 \pm 0.32)$ did not reflect the conversion by weight, whereas diet $A$ despite having a higher percentage of 
TAB LE 4 Productive parameters of Atlantic Salmon (Salmo salar) fed experimental diets for 49 days

\begin{tabular}{|c|c|c|c|}
\hline Parameter & Control & Diet A & $\begin{array}{l}\text { Relative } \\
\text { variation }\end{array}$ \\
\hline Initial weight (g) & $491.40 \pm 1.1$ & $490.00 \pm 1.1$ & $0 \%$ \\
\hline Final weight (g) & $756.90 \pm 10.4$ & $794.00 \pm 10.4$ & $5 \%$ \\
\hline $\begin{array}{l}\text { Condition } \\
\text { factor (K) }\end{array}$ & $1.35 \pm 0.0$ & $1.35 \pm 0.0$ & $0 \%$ \\
\hline $\begin{array}{l}\text { Growth in } \\
\text { weight (\%) }\end{array}$ & $54.00 \pm 2.4$ & $62.00 \pm 2.4$ & $15 \%$ \\
\hline $\begin{array}{l}\text { Feed rate } \\
\text { (\%BW/day) }\end{array}$ & $1.11 \pm 0.1$ & $1.31 \pm 0.1$ & $18 \%$ \\
\hline $\begin{array}{l}\text { Conversion } \\
\text { factor (FCR) }\end{array}$ & $1.55 \pm 0.3$ & $1.59 \pm 0.3$ & $3 \%$ \\
\hline $\begin{array}{l}\text { Standard growth } \\
\text { rate (SGR) }\end{array}$ & $0.66 \pm 0.0$ & $0.74 \pm 0.0$ & $12 \%$ \\
\hline $\begin{array}{l}\text { Coefficient of } \\
\text { thermal growth } \\
\text { (TGC) }\end{array}$ & $1.34 \pm 0.1$ & $1.51 \pm 0.1$ & $13 \%$ \\
\hline Survival (\%) & $95.70 \pm 6.1$ & $98.60 \pm 2.0$ & $3 \%$ \\
\hline
\end{tabular}

growth the conversion obtained was much higher than desired at this stage. This result may be due to diet A containing a higher percentage of lipids which apparently in the final stage of the test affected fish consumption. Studies carried out by (Kousoulaki, Mørkøre, Nengas, Berge, \& Sweetman, 2016) replacing fish oil with microalgae biomass of the Schizochytrium sp strain in Atlantic salmon indicates lower conversion factor values between 0.71 and 0.73 in the different diets where $2.5 \%$ and $5 \%$ microalgae, which is a value closer to that achieved at productive levels unlike those obtained in our trials.

The results of the muscle fatty acid profile obtained from the basal and final samples are shown in Table 5. Statistical analysis showed that there was significant difference $(p<.05)$ between the EPA content of Atlantic salmon muscle at the beginning and end of the experiment, but there was no significant differences $(p>.05)$ at the end of the experiment between the two diets assayed. In both treatments, the fatty acids content of muscle increase, especially of Arachidonic, Eicosapentaenoic and Docosohexanoic fatty acids, with values from $25 \%$ to $300 \%$ increase, demonstrating that there was a relevant increase in the accumulation of these fatty acids in the muscle in both treatments. This behaviour may be related to the fact that the microalgae biomass incorporated in "diet A" fulfils the objective of causing similar accumulation of a diet with $100 \%$ fish oil, however, it is recommended to continue testing different levels of incorporation to corroborate the results obtained in this assay. Spray dried microalgae biomass (Schizochytrium sp.) included up to $5 \%$ in extruded feeds for salmon can successfully replace fish oil as source of n-3 LC-PUFA without compromising fish growth rate and FCR, dietary protein and energy digestibility and flesh quality (Kousoulaki et al., 2016). The aquaculture industry has shown great interest in including microalgae biomass as a feed supplement in the diets used, as a sustainable alternative to fish meal and oil from wild captures, and because it is of higher quality than cereals and other raw
TABLE 5 Fatty acids content of Atlantic salmon muscle (Salmo salar) at the beginning and end of the growth experiments using control and Diet A fed

\begin{tabular}{|c|c|c|c|c|}
\hline $\begin{array}{l}\text { Type of } \\
\text { samples }\end{array}$ & Trials & Fatty acids & $\begin{array}{l}\text { Results } \\
\text { (g/100g) }\end{array}$ & $\begin{array}{l}\text { Relative } \\
\text { variation }\end{array}$ \\
\hline \multirow[t]{7}{*}{ Basal } & \multirow[t]{7}{*}{ Control } & Palmitic C16:0 & 1.11 & \\
\hline & & Oleic C18:1 & 2.29 & \\
\hline & & Linoleic C18:2 & 1.15 & \\
\hline & & Linolenic C18:3 & 0.04 & \\
\hline & & Arachidonic C20:4 & 0.01 & \\
\hline & & Eicosapentaenoic 20:5 & 0.30 & \\
\hline & & Docosohexanoic 22:6 & 0.77 & \\
\hline \multirow[t]{7}{*}{ Final } & \multirow[t]{7}{*}{ Control } & Palmitic C16:0 & 1.46 & $32 \%$ \\
\hline & & Oleic C18:1 & 3.41 & $49 \%$ \\
\hline & & Linoleic C18:2 & 1.18 & $3 \%$ \\
\hline & & Linolenic C18:3 & 0.05 & $25 \%$ \\
\hline & & Arachidonic C20:4 & 0.04 & $300 \%$ \\
\hline & & Eicosapentaenoic $20: 5$ & 0.48 & $60 \%$ \\
\hline & & Docosohexanoic 22:6 & 0.96 & $25 \%$ \\
\hline \multirow[t]{7}{*}{ Final } & \multirow[t]{7}{*}{ Diet A } & Palmitic C16:0 & 1.41 & $27 \%$ \\
\hline & & Oleic C18:1 & 3.21 & $40 \%$ \\
\hline & & Linoleic C18:2 & 1.12 & $-3 \%$ \\
\hline & & Linolenic C18:3 & 0.05 & $25 \%$ \\
\hline & & Arachidonic C20:4 & 0.04 & $300 \%$ \\
\hline & & Eicosapentaenoic $20: 5$ & 0.49 & $63 \%$ \\
\hline & & Docosohexanoic 22:6 & 0.96 & $25 \%$ \\
\hline
\end{tabular}

materials. Accordingly, the aquaculture industry requires the supply of 25,000 to 200,000 tons of microalgae biomass per year to cover the demand for the main PUFAs (EPA and DHA) (Global Salmon Initiative (GSI) Novel Oils for Salmon Aquaculture Feed, August 2015). To meet this requirement, it is still necessary to improve the performance and scale-up the existing technologies. This paper has therefore summarized the necessary steps that have to be performed, at least in the first stages of the process, however, we can contend that scaling is possible considering these systems as part of the production process for generating inoculums at a massive level and a rate of dilution from 0.2 to 0.3 per day.

\section{4 | CONCLUSION}

In this work, a full process for the production of $N$. gaditana as supplement for aquaculture is developed. A low cost culture medium prepared from fertilizers instead of pure chemicals has been developed, it allowing maximizing the performance of this strain at minimum cost. The influence of average irradiance on $N$. gaditana growth has been modelled under laboratory-controlled conditions, with the model fitting data from batch and continuous cultures. Moreover, this model fitted data from outdoor flat-panel reactors, demonstrating it as a useful tool for the scaling-up of these types 
of processes. Optimal performance of the cultures was obtained in continuous mode at $0.25 /$ day. The biochemical composition of the biomass produced is similar to that previously reported, meaning it can be incorporated into aquaculture feed up to $5 \%$. On the other hand, the omega 3 was transferred to the salmon muscle reaching values higher than the initial ones but similar to those of the control diet, which indicates that when extracting $5 \%$ of the commercial diet and replacing it with microalga, the additive was able to meet the requirements of the fish reaching values similar to those fed with usual commercial diets. However, the production capacity still has to be increased by thousands of times to fulfil the requirements of the aquaculture market.

\section{ACKNOWLEDGMENTS}

This work is part of the "Desert Bioenergy S. A" project in association with the Biotechnology Centre at Antofagasta University. It was funded by the Chilean Promotions Corporation (CORFO).

\section{REFERENCES}

Acién, F. G., Molina, E., Fernández-Sevilla, J. M., Barbosa, L., \& Gouveia, C. (2017). Economics of microalgae production. In C. Gonzalez \& R. Muñoz (Eds.), Economics of Microalgae Biomass Production. Microalgaebased biofuels and bioproducts. From Feedstock Cultivation to End-products. (PP. 485-503). Cambrigde: Woodhead Publishing Series in Energy

Acién, F. G., Fernandez, J. M., Magan, J. J., \& Molina, E. (2012). Production cost of a real microalgae production plant and strategies to reduce it. Biotechnology Advances, 30, 1344-1353.

Araujo, G. S., Matos, L. J., Gonçalves, L. R., Fernandes, F. A., \& Farias, W. (2011). Bioprospecting for oil producing microalgal strains: Evaluation of oil and biomass production for ten microalgal strains. Bioresource Technology, 102, 5248-5250.

Breuer, G., Lamers, P., Martens, D., Draaisma, R., \& Wijffels, R. (2012). The impact of nitrogen starvation on the dynamics of triacylglycerol accumulation in nine microalgae strains. Bioresource Technology, 124, 217-226.

Camacho, J., González, A., Cerón, M., Fernández, J., Acién, F., \& Molina, E. (2014). A quantitative study of eicosapentaenoic acid (EPA) production by Nannochloropsis gaditana for aquaculture as a function of dilution rate, temperature and average irradiance. Applied Microbiology and Biotechnology, 98, 2429-2440.

Camacho-Rodríguez, J., Cerón-García, M. C., Fernández-Sevilla, J. M., \& Molina-Grima, E. (2015). The influence of culture conditions on biomass and high value product generation by Nannochloropsis gaditana in aquaculture. Algal Research, 11, 63-73.

Canavate, J. P. (2017). Las algas como recurso. Valorización. Aplicaciones industriales y tendencias. Retrievd from https://www.researchgate.ne t/publication/235960627

Chini, G., Rodolfi, L., Biondi, N., \& Tredici, M. (2006). Productivity and photosynthetic efficiency of outdoor cultures of Tetraselmis suecica in annular columns. Aquaculture, 261, 932-943.

Chisti, Y. (2013). Constraints to commercialization of algal fuels. Journal of Biotechnology, 167, 201-214.

Doucha, J., \& Lívanský, K. (1995). Novel outdoor thin-layer high density microalgal culture system: Productivity and operation parameters. Archive Hydrobiol/Algol Stud, 76, 129-147.

Fernández-Sevilla, J. M., Acién Fernández, F. G., \& Molina Grima, E. (2010). Biotechnological production of lutein and its applications. Applied Microbiology and Biotechnology, 86, 27-40.
Geider, R., \& Roche, J. La (2002). Redfield revisited : variability of C : N : $P$ in marine microalgae and its biochemical basis Redfield revisited : variability of $C: N: P$ in marine microalgae and its biochemical basis. European Journal of Phycology, 37, 1-17.

González, A., Tabernero, A., Sánchez, J., Martin del Valle, E., \& Galán, M. (2014). Effect of nitrogen source on growth and lipid accumulation in Scenedesmus abundans and Chlorella ellipsoidea. Bioresource Technology, 173, 334-341.

González-López, C. V., Cerón-García, M. C., Fernández-Sevilla, J. M., González-Céspedes, A. M., Camacho-Rodríguez, J., \& Molina-Grima, E. (2013). Medium recycling for Nannochloropsis gaditana cultures for aquaculture. Bioresource Technology, 129, 430-438.

Gouveia, L., \& Oliveira, A. C. (2009). Microalgae as a raw material for biofuels production. Journal of Industrial Microbiology and Biotechnology, 36, 269-274.

Griffiths, M. J., van Hille, R. P., \& Harrison, S. T. L. (2012). Lipid productivity, settling potential and fatty acid profile of 11 microalgal species grown under nitrogen replete and limited conditions. Journal of Applied Phycology, 24, 989-1001.

Grima, E. M., Sevilla, J. M. F., Pérez, J. A. S., Camacho, F. G., Molina Grima, E., Fernández Sevilla, J. M., ... García Camacho, F. (1996). A study on simultaneous photolimitation and photoinhibition in dense microalgal cultures taking into account incident and averaged irradiances. Journal of Biotechnology, 45, 59-69.

Hu, Q., Sommerfeld, M., Jarvis, E., Ghirardi, M., Posewitz, M., Seibert, M., \& Darzins, A. (2008). Microalgal triacylglycerols as feedstocks for biofuel production: Perspectives and advances., 54, 621-639.

Huang, Q., Yao, L., Liu, T., \& Yang, J. (2012). Simulation of the light evolution in an annular photobioreactor for the cultivation of Porphyridium cruentum. Chemical Engineering Science, 84, 718726.

Huertas, E. (2000). Effects of dissolved inorganic carbon availability on growth, nutrient uptake and chlorophyll fluorescence of two species of marine microalgae. Aquacultural Engineering, 22, 181-197.

Huntley, M. E., \& Redalje, D. G. (2007). CO2 mitigation and renewable oil from photosynthetic microbes: A new appraisal. Mitigation and Adaptation Strategies for Global Change, 12, 573-608.

Jaime-Ceballos, B. J., Hernández-Llamas, A., Garcia-Galano, T., \& Villarreal, H. (2006). Substitution of Chaetoceros muelleri by Spirulina platensis meal in diets for Litopenaeus schmitti larvae. Aquaculture, 260, 215-220.

Kousoulaki, K., Mørkøre, T., Nengas, I., Berge, R. K., \& Sweetman, J. (2016). Microalgae and organic minerals enhance lipid retention ef $\mathrm{fi}$ ciency and fi llet quality in Atlantic salmon (Salmo salar L.). Aquaculture, 451, 47-57.

Lagus, A. (2009). Role of nutrients in regulation of the phytoplankton community in the archipelago sea. Thesis, University of Turky.

Lem, A., Bjorndal, T., \& Lappo, A. (2014). Economic analysis of supply and Role of nutrients in regulation of the phytoplankton community in the archipelago seademand for food up to 2030 - special focus on fish and fishery products.

Li, Q., Du, W., \& Liu, D. (2008). Perspectives of microbial oils for biodiesel production. Applied Microbiology and Biotechnology, 80, 749-756.

Molina Grima, E., Garcia Camacho, F., Sanchez Perez, J. A., Acien Fernandez, F. G., \& Fernandez Sevilla, J. M. (1997). Evaluation of photosynthetic efficiency in microalgal cultures using average irradiance. Enzyme and Microbial Technology, 21, 375-381.

Molina, E., Fernández, J., Acién, F. G. G., \& Chisti, Y. (2001). Tubular photobioreactor design for algal cultures. Journal of Biotechnology, 92, 113-131.

Muller-Feuga, A. (2000). The role of microalgae in aquaculture: Situation and trends. Journal of Applied Phycology, 12, 527-534.

Norsker, N-H., Barbosa, M. J., Vermuë, M. H., \& Wijffels, R. H. (2011). Microalgal production-a close look at the economics. Biotechnology advances, 29, 24-27. 
Oswald, W. J., \& Golueke, C. G. (1968). Large scale production of microalgae. In R. I. Mateless, \& S. R. Tannenbaum (Eds.), Single cell protein (pp. 271-305). MA: MIT Press Cambridge.

Rodolfi, L., Zittelli, G. C., Bassi, N., Padovani, G., Biondi, N., Bonini, G., \& Tredici, M. R. (2009). Microalgae for oil: Strain selection, induction of lipid synthesis and outdoor mass cultivation in a low-cost photobioreactor. Biotechnology and bioengineering, 102, 100-112.

Ryckebosch, E., Bruneel, C., Termote-verhalle, R., Goiris, K., Muylaert, K., \& Foubert, I. (2014). Nutritional evaluation of microalgae oils rich in omega-3 long chain polyunsaturated fatty acids as an alternative for fish oil. Food Chemistry, 160, 393-400.

San Pedro, A., González-López, C. V., Acién, F. G., \& Molina-Grima, E. (2014). Outdoor pilot-scale production of Nannochloropsis gaditana: Influence of culture parameters and lipid production rates in tubular photobioreactors. Bioresource technology, 169, 667-676.

San Pedro, A., González-López, C. V. V., Acién, F. G. G., \& Molina-Grima, E. (2015). Outdoor pilot production of nannochloropsis gaditana: Influence of culture parameters and lipid production rates in raceway ponds. Algal Research, 8, 205-213.

Sepúlveda, C., Acién, F. G., Gómez, C., Jiménez-Ruíz, N., Riquelme, C., \& Molina-Grima, E. (2015). Utilization of centrate for the production of the marine microalgae Nannochloropsis gaditana. Algal Research, 9, 107-116.

Spolaore, P., Joannis-Cassan, C., Duran, E., \& Isambert, A. (2006). Commercial applications of microalgae. Journal of Bioscience and Bioengineering, 101, 87-96.
Torzillo, G., Zittelli, G. C., \& Chini Zittelli, G. (2015). Tubular Photobioreactors. In A. Prokop, R. K. Bajpai \& M. E. Zappi (Eds.), Algal biorefineries volume 2: Products and refinery design (pp. 187-212). Switzerland: Springer International Publishing.

Tredici, M. R., Bassi, N., Prussi, M., Biondi, N., Rodolfi, L., Chini Zittelli, G., \& Sampietro, G. (2015). Energy balance of algal biomass production in a 1-ha "Green Wall Panel" plant: How to produce algal biomass in a closed reactor achieving a high Net Energy Ratio. Applied Energy, 154, 1103-1111.

Wijffels, R. H., \& Barbosa, M. J. (2010). An outlook on microalgal biofuels. Science, 329, 796-799.

Zou, N., \& Richmond, A. (1999). Effect of light-path length in outdoor fiat plate reactors on output rate of cell mass and of EPA in Nannochloropsis sp. Progress in Industrial Microbiology, 35, 351-356.

How to cite this article: Riveros K, Sepulveda C, Bazaes J, Marticorena P, Riquelme C, Acién G. Overall development of a bioprocess for the outdoor production of Nannochloropsis gaditana for aquaculture. Aquac Res. 2018;49:165-176. https://doi.org/10.1111/are.13445 